\title{
SISTEM KEAMANAN RUMAH BERBASIS INTERNET OF THINGS
}

\author{
Muchamad Sobri Sungkar \\ Email : sobrisungkar@gmail.com \\ Teknik Elektronika Politeknik Harapan Bersama Tegal
}

\begin{abstract}
Abstrak
Saat ini tindak kriminalitas perampokan dan pencurian di rumah tangga masih banyak dan meresahkan. Hal ini disebabkan tingkat pengangguran yang meningkat setiap tahun. Pengangguran umumnya disebabkan karena jumlah angka kerja tidak sebanding dengan jumlah lapangan kerja. Rumah merupakan salah satu kebutuhan pokok dalam kehidupan manusia. Sebuah rumah harus menyediakan rasa aman bagi pemiliknya. Pada penelitian sebelumnya, sistem keamanan rumah hanya menggunakan sms gateway. Oleh karena itu, untuk memperbaiki teknologi tersebut, dibuatlah suatu sistem keamanan rumah berbasis mikrokontroler dan IoT. Komponen elektronik terdiri dari sebuah sensor IR, dan komponen pendukung lain sebagai pelengkap. Sistem tersebut akan dilengkapi juga dengan pengambilan gambar sebagai alat pemberitahuan kepada pemilik rumah. Hasil dari penelitian ini menunjukkan bahwa sensor IR berfungsi dapat mendeteksi sesuatu. Uji coba membuktikkan bahwa pesan dapat terkirim ketika sensor mendeteksi sesuatu. Sedangkan jarak yang jauh sistem masih bisa berfungsi selagi masih terkoneksi internet
\end{abstract}

Kata Kunci : Sistem Keamanan Rumah, Wemos D1, Mikrokontroler, IOT, Arduino.

\section{Pendahuluan}

Sistem keamanan digunakan untuk memberikan perlindungan pada suatu benda dimana suatu benda itu berisi sesuatu yang dirasa sangat berharga dan perlu diberikan pengamanan seperti suatu bangunan, tempat maupun yang diangap berharga. Oleh karna itu sistem kemanan di perlukan untuk mencegan seseorang melakukan tindak kejahatan baik pencurian ataupun tindak kriminal. Khususnya pada daerah yang kurang cepat penangan saat terjadi tindak kehajatan karna akan merugikan ketika yang dianggap berharga hilang.

Sistem yang digunakan untuk penelitan ini adalah suatu system pengamanan rumah, kita semua meyakini bahwasanya rumah merupakan tempat yang paling aman dan nyaman untuk menyimpan benda berharga. Sistem pengamanan yang dibuat untuk melakukan suatu pengawasan terhadapa seseorang dalam memonitoring pergerakan orang yang akan memasuki rumah dalam melakukan suatu pencegahan dari sesuatu yang tidak dikehendaki oleh pemilik rumah, contoh pencuri maupun tindak kirminal lainnya. Hal ini di buat menggunakan wemos d1 (sebagai system IOT) [1]. Kamera sebagai media pengawas, sensor IR dan buzzer sebagai alarm ketika ada yang memaksa masuk rumah atau melewati sensor IR. Kelebihan sistem ini yaitu system ini dapat melakukakn pengawasan orang yang akan memasuki rumah atau melewati sensor yang di pasang serta dapat menyalakan alarm dan lampu secara otomatis.

Sedangkan pada penelitian ini, sistem keamanan yang dirancang lebih sederhana dikarenakan hanya menggunakan wemos d1 dan digunakan SD Card Shield sebagai media penerima data dari vc0706 yang manaadakan tersimpan pada sd card dan lampu, buzzer akan menyala secara otomatis ketika ada yang masuk secara paksa.

\section{Metode Penelitian}

perancangan suatu sistem pengamanan rumah menggunakan Internet of Things ini dilakukan menggunakan suatu cara deskriptif, jadi penelitian yang dibuat ini karena terdapat beberapa kejadian yang menjadikan pengalaman atau inspirasi dalam melakukan upaya pengamanan rumah.

Untuk dapat melakukan perancangan sistem pengamanan rumah berbasiskan Internet of Thingsdengan melakukan pemasangan suatu komponen hardware dari sebuah system pengamanan ini. Perangkat yang terlebih dahulu dirancang adalah wemos d1, wemos d1 berfungsi sebagai sistem IOT pada alat yang akan di buat dan merespon suatu inputan yang sudah di atur dalam suatu program arduino agar dapat berguna dalam melakukan pemrosesan dari berbagai peripheral - periperal yang terhubung. step berikutnya yaitu melakukan instalasi software Arduino ide dimana berfungsi sebagai tool dalam menuliskan program yang akan di buat[2] .

Untuk memastikan semuanya bekerja dengan baik dilakukan pengujian system mengunakan software proteus dimana sofware ini dapat melakukan simulasi agar system yang dibuat sesuai dengan apa yang telah direncanakan. Berikut Gambar 1 untuk penjelasannya. 


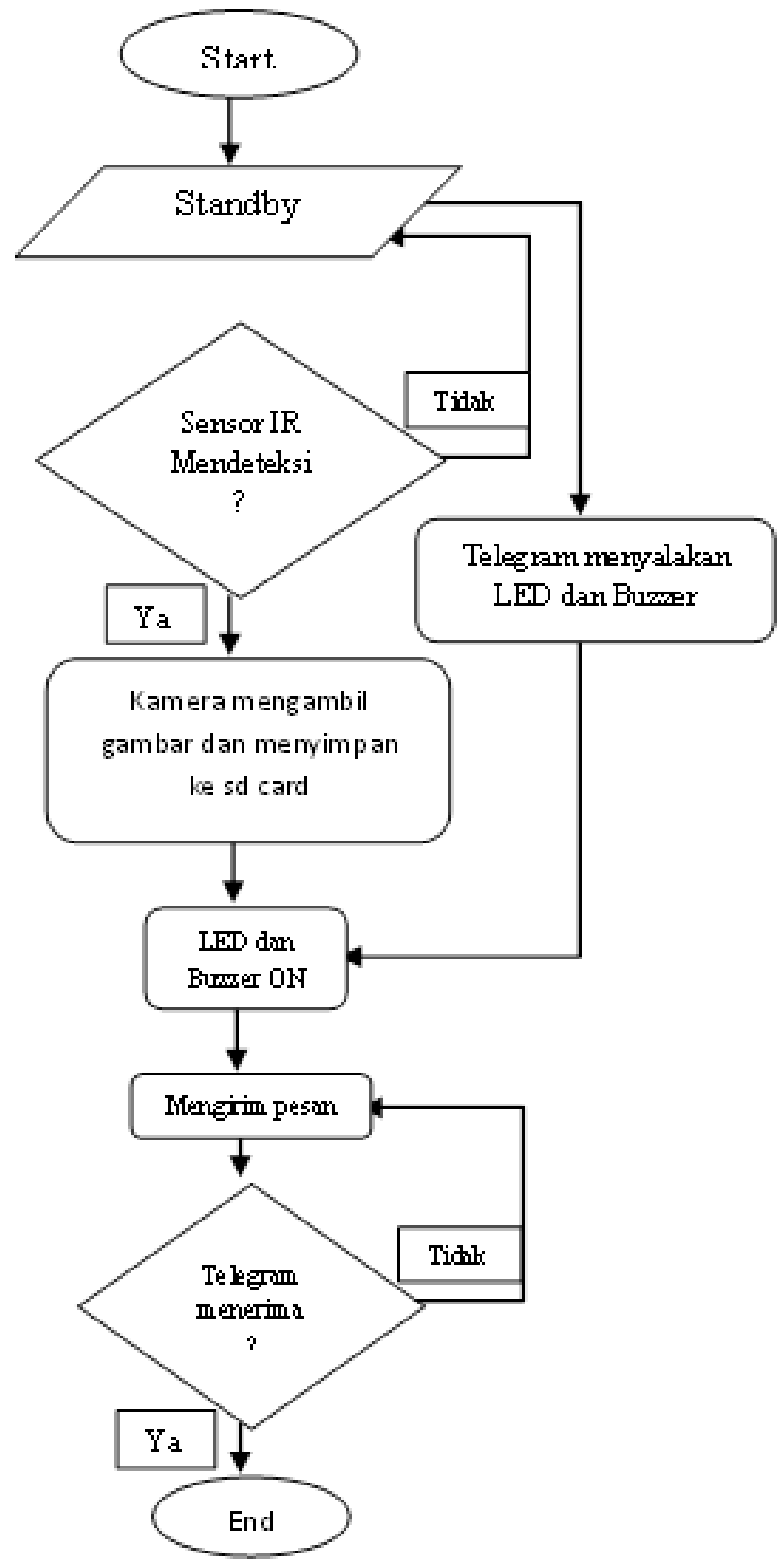

Gambar 1. Flowchart Program

Cara kerja sistem ini adalah Ketika sensor IR aktif maka Buzzer dan LED akan menyala kemudian kamera akan mengambil gambar dan mengirimkan pesan ke aplikasi telegram sampai diterima oleh aplikasi telegram. Dan pada saat posisi stanby aplikasi telegram bisa mengirim pesan untuk menyalakan atau mematikan alarm, ketika pesan diterima, program akan meyalakan atau mematikan alarm.

\section{Hasil dan Pembahasan}

Perancangan telah terlaksana setelah itu dilakukanlah uji coba terhadap sistem keamanan rumah berbasis IOT dengan melakukan pengamatan terhadap sensor IR serta proses pengujian waktu penyimpanan gambar kedalam SD Card.

Dalam pengujian sistem otomatis keamanan rumah ini dibutuhan langkahlangkah sebagai berikut:

1. Kondisi alat dalam keadaan standby.

2. Ketika sensor IR dalam kondisi High (mendeteksi) maka buzzer dan LED akan menyala, program akan mengirimkan pesan ke Telegram, kemudian kamera akan mengambil gambar dan disimpan pada $S D$ Card

3. Buzzer dan LED akan mati setelah waktu yang ditentukan habis.

Table 4.1 Hasil Pengujuan Sensor IR

\begin{tabular}{|c|c|c|}
\hline NO & Jarak Deteksi & Kondisi Infrared \\
\hline 1. & $2 \mathrm{~cm}$ & AKTIF \\
\hline 2. & $5 \mathrm{~cm}$ & AKTIF \\
\hline 3. & $7 \mathrm{~cm}$ & AKTIF \\
\hline 4. & $10 \mathrm{~cm}$ & AKTIF \\
\hline 5. & $12 \mathrm{~cm}$ & AKTIF \\
\hline 6. & $15 \mathrm{~cm}$ & TIDAK AKTIF \\
\hline
\end{tabular}

Dalam pengujian sistem otomatis keamanan rumah ini dibutuhan langkahlangkah sebagai berikut:

1. Kondisi alat pada keadaan standby.

2. Ketika sensor IR dalam kondisi High (mendeteksi) maka buzzer dan LED akan menyala, program akan mengirimkan pesan ke Telegram, kemudian kamera akan mengambil gambar dan disimpan pada $S D$ Card

3. Buzzer dan LED tetap dalam keaadan hidup.

Table 4.2 Hasil Pengujiuan Waktu Penyimpanan Gambar

\begin{tabular}{|c|c|c|}
\hline NO & Kualitas Gambar & Waktu \\
\hline 1. & $640 \times 480$ & 26.5 detik \\
\hline 2. & $320 \times 240$ & 25.7 detik \\
\hline 3. & $160 \times 120$ & 23.4 detik \\
\hline
\end{tabular}

\section{Kesimpulan}

Setelah melakukan uji coba dan analisa terhadap hasil sistem kemanan rumah maka dapat disimpulkan sebagai berikut :

1. Deteksi dari sensor IR pada jarak $2 \mathrm{~cm}-$ $12 \mathrm{~cm}$ menghasilkan kondisi aktif dan pada jarak $15 \mathrm{~cm}$ menghasilkan kondisi tidak aktif.

2. Penyimpanan foto dari program ke SD Card membutuhkan waktu 25 detik. 


\section{Daftar Pustaka}

[1] Nugroho Adi Trio.,dkk "Model Sistem Keamanan Ruangan Menggunakan GSM Shield Dan Kamera CCTV Berbasis Arduino", Universitas Pakuan, 2016

[2] M. P. T. Sulistyanto and D. A. Nugraha, "Implementasi IoT (Internet of Things) dalam pembelajaran di Universitas Kanjuruhan Malang," SMARTICS Journal, pp. 20-23, 2015

[3] Sulaiman Oris Krianto, Adi Widarma, "SISTEM INTERNET OF THINGS (IOT) BERBASIS CLOUD COMPUTING DALAM CAMPUS AREA NETWORK", Universitas Negeri Medan,2017

[4] Tri Rahajoeningroem, Wahyudin "SISTEM KEAMANAN RUMAH DENGAN MONITORING MENGGUNAKAN JARINGAN TELEPON SELULAR", Universitas Komputer Indonesia ,2013

[5] Eka Permana, Ridwan Hidayat "RANCANG BANGUN SISTEM KEAMANAN RUMAH BERBASIS SMS GATEWAY MENGGUNAKAN MIKROKONTROLER", STMIK Subang, 2017

[6] Wikipedia Bahasa Indonesia, "Keamanan", Wikipedia, [Online]. Tersedia: https://id.wikipedia.org/wiki/Keamanan. [Diakses: 3-Januari-2019].

[7] Shofia Khoirunnisa, "SISTEM PEMANTAUAN DENYUT NADI DENGAN MENGGUNAKAN INTERNET OF THINGS", POLITEKNIK NEGERI BANDUNG, 2017

[8] Safei Imam, "Pengembangan Teknologi Alat Ukur Tes Split Berbasis Arduino Dan Sensor Dengan Led Display", Universitas Lampung, 2018.

[9] Farhan, "PENGAMBILAN FOTO SECARA REALTIME DENGAN MENGGUNAKAN KOMUNIKASI WIRELESS", Politeknik Negri Batam, 2017.

[10] Nugroho Dimas, "INTEGRASI APLIKASI TELEGRAM UNTUK MONITORING DAN KEAMANAN KENDARAAN BERMOTOR BERBASIS ARDUINO DAN OPENWRT', Universitas Amikom Yogyakarta, 2018.
[11] Diding Suhardi, "Prototipe Controller Lampu Penerangan LED (Light Emitting Diode) Independent Bertenaga Surya", Jurnal GAMMA,vol.10,No.1, pp. 116122,Sep. 2014.

[12] POLSRI Repository, "Arduino", POLSRI Repository [Online]. Avaible: http://eprints.polsri.ac.id/3625/3/FILE\%2 0III.pdf [Accessed 28-Dec-2018] 